\title{
PERFORMANCE OF SUPPLY CHAIN IN AN UNCERTAIN ENVIRONMENT USING FUZZY LOGIC
}

\author{
Vijay Kumar Dwivedi ${ }^{1}$, Pooja Pathak² \\ 1,2 GLA University, Mathura, India \\ 1vijay.dwivedi@gla.ac.in
}

\begin{abstract}
-
A real Supply Chain (SC) functions in an uncertain environment. Different type of uncertainties exist along the SC. These are random. Uncertainty appears in customer demand, production and supply. The SC models developed till now either neglect uncertainty or considered it approximately by the use of probability concepts. This paper concentrates on developing a fuzzy model for analyzing supply chain dynamics and measures of performance during a finite time horizon. It has been seen that uncertain customer demand and uncertain supply along the supply chain have great impact on supply chain behavior. In this paper satisfaction of customer is examined in an uncertain environment using fuzzy concept. This model gives very useful results to understand the real situation of the demand and production. These models help to reduce lead time, holding cost and maximize the profit as well. The proposed scheme provides managerial insights on the impact of the decision making in all the supply chain elements including suppliers, manufacturers, warehouses, transporters, retailers, and customers.
\end{abstract}

Key words: Supply chain, uncertain environment, fuzzy logic.

\section{I.INTRODUCTION}

Supply chain (SC) management is a set of approaches utilized to efficientely integrate suppliers, manufacturers, warehouses and stores so that merchandise is produced and distributed at the right quantities, to the right location and at the right time, in order to minimize system wide costs while satisfying service level requirements. The optimization criteria have imprecise values for each ordering policy. This ascertain is based on the fact that relations between elements of supply chain critically depend on human activities. This facts is one of the main reasons why emergent supply chain system requires fuzzy system modeling. The values of uncertain optimization criteria can be described by discrete fuzzy members. The fuzzy approach to treating uncertainity has some advantages over the stochastic approach:

- Calculation of probability distribution for each stochastic variable request a lot of evidence.

- Combining of different uncertainities leads to a complex probability distribution, this results in very complex mathematical expressions.

Supply chain as a complex system with imprecise parameters and conditions can be analyzed and modeled with the application of fuzzy set theory more appropriately.

\section{II.LITERATURE REVIEW}

Petrovic et al.(1998, 1999, 2001) have carried out their research in the area of supply chain by using fuzzy sets to reduce the uncertainy. Liong et al. (2002) presented a fuzzy based supply chain management decision support system. Giannoccaro et al. (2003) have given the idea of fuzzy echelon approach for inventory management in supply chains. Kishore et al. (2003) presented a fuzzy TOPSIS approach for evaluation of production facility in a close loop supply chain. Kumar et al. (2004) uses fuzzy concept in goal programming for vender selection problem in supply chain. Zarandi et al. (2007) presented five crisp and fuzzy models for supply chain of the automotive manufacturing system and compare the outputs.

\section{III.UNCERTAINITY IN SUPPLY CHAIN (SC)}

A real SC operates in an uncertain environment. Different sources and types of uncertainity exist along the SC. They are random events, uncertainty in judgement and lack of evidence that appear in customer demand, production and supply. Each facility in the SC must deal 
with uncertain demand imposed by succeeding facilities and uncertain delivery of the proceding facilities in the SC. The SC models developed so far either ignored uncertainty or considered it approximately through ther use of probability concepts.

\section{A. Machine uncertainity}

The machine dynamic behavior is the most important factor in manufacturing system. The machine lifetime, breakdown conditions, maintenance, time between failures, time between repairs and quality are necessary to address in order to improve the accuracy of simulation resources. Those must take into account fuzzy dynamics for a realistic scenario.

\section{B. Labor uncertainity}

Labour dynamics are considered for better representation of the operator performance on the shop floor. The operators are classified as skilled, medium and normal. The working environment is also another factor for labour dynamics. The working environment is considered as good, fair and poor. The absence rate is also another factor in shop floor assembly system. The absentee rate is considered as long, medium and short.

\section{Demand uncertainity}

The demand behavior is also an important factor in manufacturing system. This uncertainity is expressed in questions such as: what will my customer order? How many products we have in stock? The presence of uncertainty stimulate the decision maker to create safety buffers in time, capacity or inventory to avoid a bad chain performance.

\section{Raw material uncertainity}

Companies in any manufacturing sector are always looking for low-cost raw material, domestic or imported. With the objective of improving their competitive advantage, some of them see importing as an appealing option. As there are some advantages when importing resources, such as lower labor cost and lower cost of resources. Importing raw materials, components or products increases the dependence on suppliers (Lockamy and McCormack, 2010), and some risks are identified such as culture, language, foreign exchange rate, regulations, quality, political and economic stability, and transportation delays (Canbolat et al., 2008).

\section{E. Due Date uncertainity}

The due dates for individual orders are set entirely remote. However, in certain practical contexts, each order arrives with a due date, indicating some future time when the customer wishes to receive the goods ordered and, in most cases, due date setting is negotiable and is the responsibility of the marketing personnel of the firm. For the marketing group, who have knowledge of customers' wishes, it is important to know their manufacturing personnel's perspective on the order before negotiating the due date with their customer. Uncertainties in manufacturing environments play important roles in determining planned customer order leadtimes. These uncertainties are mostly due to complicated production processes, random yields, and high quality requirements.

\section{MODELING OF FUZZY SATISFACTION SYSTEM}

Figure 1 shows the control mechanism of such system. The fuzzy logic based expert system consists of four components: Fuzzification (b) Rule base Inference engine (d) Defuzzification Figure 2 shows the membership fuction of input and out variables. Figure 3 present the proposed fuzzy model. A rule base is then constructed which will be based on all the applicable input parameters. For each decision several rules are fired. Table 1 shows a variations for input for the system under consideration. Table 2 shows a variations of output for the system under consideration.These variations result in an aggregate fuzzy set that represents a particular decision regarding the processing of the output. This fuzzy set is then converted into a crisp number, which depicts the degree of suitability of the decision regarding the processing of the satisfaction. The rules aggregation is done using fuzzy MOM (Mean of Maxima) algorithm. Mamdani implication is used to represent the meaning of "IF-THEN" rules. In this context, the statement "if $X$ is $A$ then $Y$ is $B$ " or

$\mathrm{A} \rightarrow \mathrm{B}$ results in a relation $\mathrm{R}$ such that $\mu_{X}(X, Y)=\min \left(\mu_{A}(X), \mu_{B}(Y)\right)$. This implication is precise, computationally simple, and fits various practical applications. The min operator is a natural choice for the logical AND. 


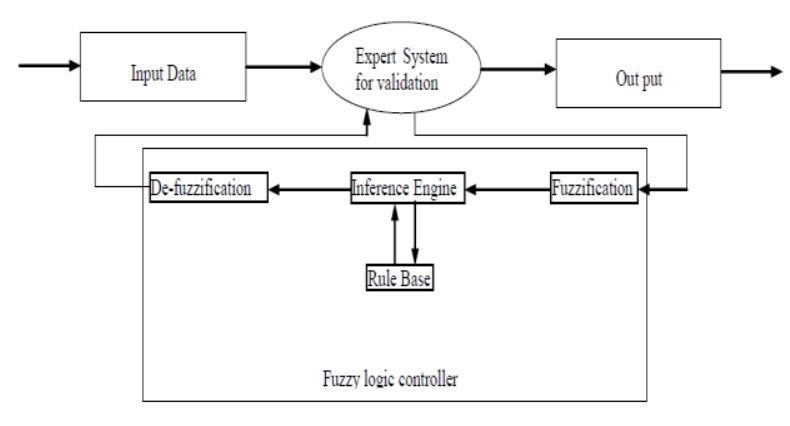

Fig 1. Fuzzy expert System
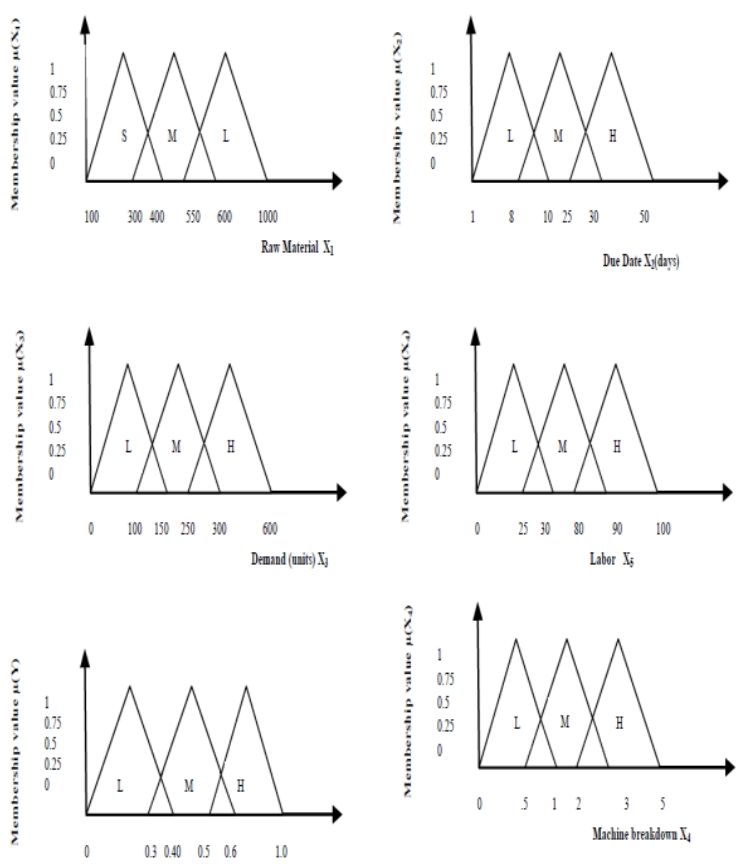

Figure 2 Membership function of input and output variable

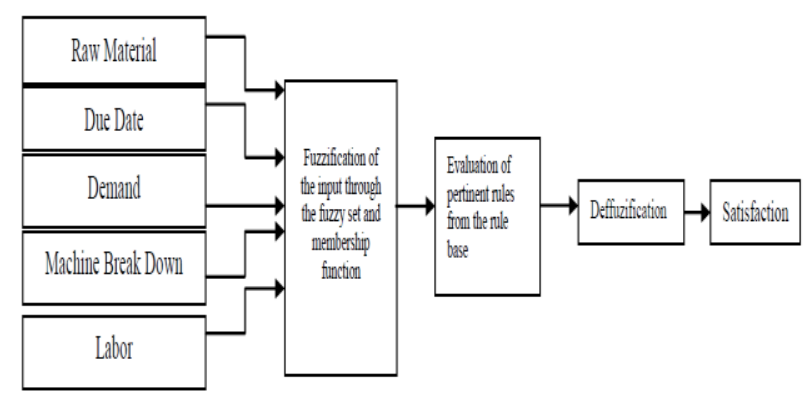

Fig 3 Fuzzy model for proposed system

Table 1 Variation of input variables

\begin{tabular}{|c|c|c|c|}
\hline Input Variables & Low/Short & Medium & High/Long \\
\hline $\begin{array}{c}\text { Raw } \\
\text { Material(pieces) }\end{array}$ & $100-400$ & $300-600$ & $550-1000$ \\
\hline Due Date (days) & $1-10$ & $8-30$ & $25-50$ \\
\hline Demand (units) & $0-150$ & $100-300$ & $250-600$ \\
\hline $\begin{array}{c}\text { Machine Break } \\
\text { Down (times per } \\
\text { day) }\end{array}$ & $0-1$ & $1-3$ & $3-5$ \\
\hline Labor (units) & $0-30$ & $30-90$ & $80-100$ \\
\hline
\end{tabular}

Table 2 Variation of output variables

\begin{tabular}{|c|c|c|c|}
\hline Output Variable & Low & Medium & High \\
\hline Satisfaction & $0-0.4$ & $0.3-0.6$ & $0.5-1$ \\
\hline
\end{tabular}

\section{V.RESULT ANALYSIS}

While generating the fuzzy model's linguistic variables, the company's own linguistic variables are considered which are used for satisfaction terms. Raw material is one of the input in the model which is linguistic variables are "Low", "Medium" and "High". Labor, and machine breakdown inputs linguistic variables are "Low", "Medium" and "High". Due date's inputs linguistic variables are "Short", "Medium", and "Long". Satisfaction output's linguistic variables are "Low", "Medium", "High" . The constraints of the linguistic variables are shown in Table 1 and Table 2, are taken from the experts of production planning.

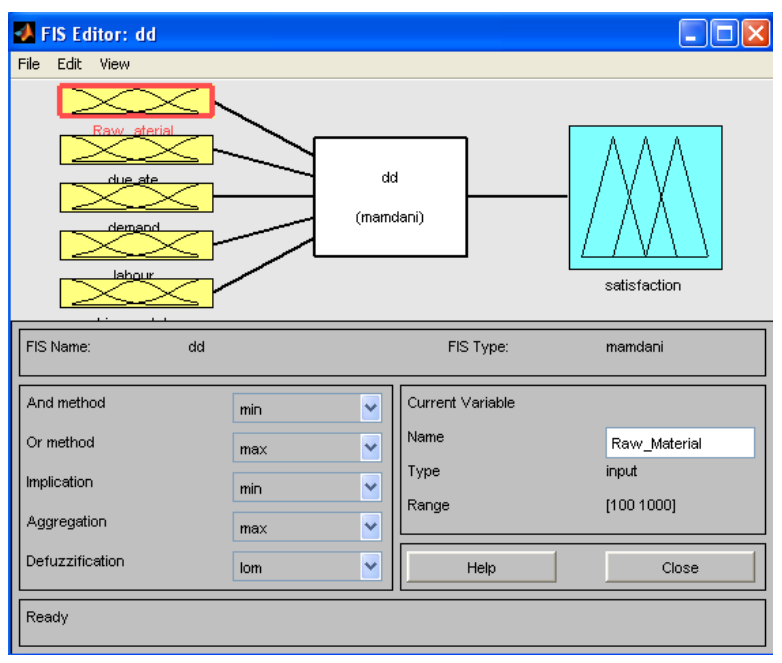

Fig 4 FIS model for satisfaction level of company 
Table 3 and Table 4 present the required data of four different manufacturing companies for diesel engine auto parts.

Table 3. Data of manufacturing companies

\begin{tabular}{|l|l|l|l|l|l|}
\hline & $\begin{array}{l}\text { Raw } \\
\text { Material } \\
\text { (pieces) }\end{array}$ & $\begin{array}{l}\text { Due Date } \\
\text { (days) }\end{array}$ & $\begin{array}{l}\text { Demand } \\
\text { (units) }\end{array}$ & $\begin{array}{l}\text { Machine Break } \\
\text { Down } \\
\text { (times per day) }\end{array}$ & $\begin{array}{l}\text { Labor } \\
\text { (units) }\end{array}$ \\
\hline Company A & 300 & 10 & 200 & 2 & 25 \\
\hline Company B & 500 & 25 & 250 & 1 & 40 \\
\hline Company C & 700 & 20 & 400 & 3 & 60 \\
\hline Company D & 900 & 35 & 550 & 4 & 80 \\
\hline
\end{tabular}

Table 4. Comparison of results of manufacturing companies

\begin{tabular}{|c|c|c|}
\hline Company & $\begin{array}{c}\text { Company's Current } \\
\text { satisfaction index }\end{array}$ & $\begin{array}{c}\text { Fuzzy Results(satisfaction } \\
\text { index) }\end{array}$ \\
\hline Company A & 0.40 & 0.36 \\
\hline Company B & 0.37 & 0.32 \\
\hline Company C & 0.22 & 0.26 \\
\hline Company D & 0.54 & 0.50 \\
\hline
\end{tabular}

After examining the linguistic variables, membership functions are determined.The Fuzzy Inference System (FIS) for input and output variables is shown in Figure 4. In this figure, inputs variables are shown in the left side and output variable is shown in the right side.

After the membership functions are determined, the rules are designated. Inputs are solved according to changing input positions for solving of fuzzified systems. With five inputs variables each having three levels, total 243 rules are developed. Here is an example of one rule is given. (Fig $5 \& 6$ )

If (Raw Material is LOW) and (Due Date is LONG) and (Demand is LOW) and (Labor is HIGH) and (Machine Breakdown is LOW) then (Satisfaction is LOW). Similarly 242 rules are developed.

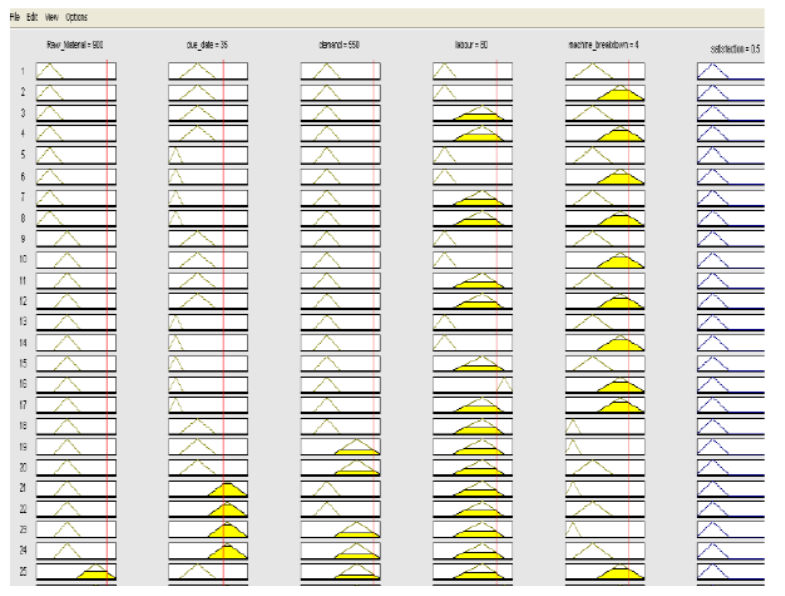

Fig 5 View of Matlab Fuzzy Toolbox: Rule Viewer for company D”.

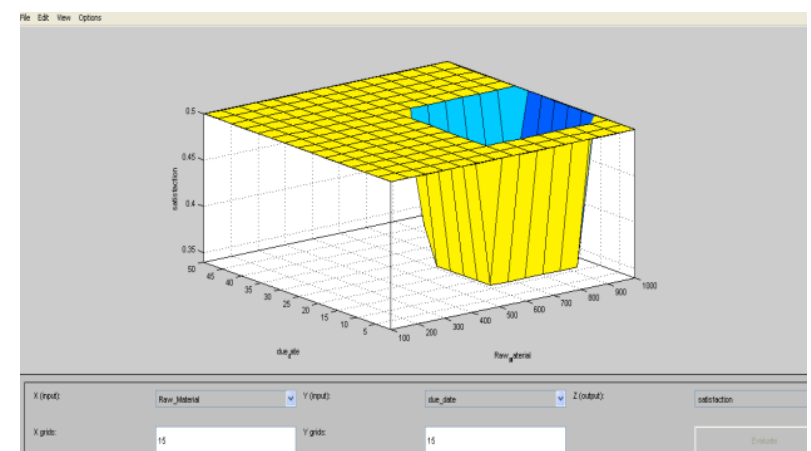

Fig 6 Surface Analysis between Raw Material and Due Date with Satisfaction

\section{VI.CONCLUSION}

This paper is intended to use fuzzy logic in SCM for finding the satisfaction of customer. Satisfaction is obtained by considering Raw Material(pieces), Due Date (days), Demand (units), Machine Break Down (times per day), Labor (units) using the fuzzy logic is important as it gives the optimal result.

Many manufacturing companies do not consider customer satisfaction result which increase the total cost and decrease the total profit. So it is very necessary to know the satisfaction of the customer at planning stage. Fuzzy logic helps to find these optimal results if the company's forecasting data are available. In this research, using historical and forecasted data of some manufacturing companies the final result is obtained by which satisfaction is determined. Here, five input variables considered to find satisfaction of customer. Some other input variables may be considered to find the result which depends on type of the production system of company. For each input and output variable Gaussian membership functions are considered to design the model. Other membership functions also may be considered to design the model. Based on the satisfaction of customers, more effective scheduling can be performed including related variables. Raw material and finished goods inventory can also be optimized in similar way.

\section{REFERENCES}

[1] Canbolat Y, Gupta G, Matera S, Chelst K. A., 2008, Analysing risk in sourcing design and manufacture of components and sub-systems to emerging markets. International Journal of Production Research, 46, pp. 51455164. 
[2] Danijela, T., 2005, Fuzzy multi-criteria approach to ordering policy ranking in a supply chain. Yugoslav of Operation Research, 15 (3), pp. 243-258.

[3] Giannoccaro, I., Pontrandolfo, P. and Scozzi, B., 2003, A fuzzy echelon approach for inventory management in supply chains. European Journal of Operation Reasearch, 149, pp.185-196.

[4] Hao, L., Zhou, Wu and Quidi, Wu., 2002, A fuzzy based supply chain management decision support system. Proceeding of the Fourth Congress on Intelligent Control and automation, June 10-14, Shanghai, P. R. China. Kumar, M., Vrat, P. and Shankar, R., 2004, A fuzzy goal programming approach for vendor selection problem in a supply chain. Journal of Computer and Industrial Enginnering, 46, pp. 69-85.

[5] Lockamy A, McCormack K., 2010, Analysing risks in supply networks to facilitate outsourcing decisions. International Journal of Production Research ,48, pp. 593-599.

[6] Pathak. P. and Dwivedi V. K., 2013, Fuzzy based pricing model for old age insurance, International Journal for Fuzzy Logic Systems, 3 (1), pp. 47-54
[7] Petrovic, D., Roy, R. and Petrovic, R., 1998, Modeling and simulation of a supply chain in an uncertain environment. European Journal of Operation Reasearch, 109, pp. 299309.

[8] Petrovic, D., Roy, R. and Petrovic, R., 1999, Supply chain modeling using fuzzy sets. International Journal of Production Economics, 59, pp. 443-453.

[9] Petrovic, D., 2001, Simulation of a supply chain behavior in an uncertain environment. International Journal of Production Economics, 71, pp. 419-428.

[10] Pochampally, K. K., Gupta, S.M. and Kamrathi, S.V., 2003, Evaluation of production facility in a close loop supply chain: A fuzzy TOPSIS approach. Proceeding of the SPIE, 5262, pp. 125-138.

[11] Zaradani, M.H.F., Zaradani, M.M.F. and Saghiri, S., 2007, Five crisp and fuzzy models for supply chain of an automotive manufacturing system. International Journal of Management Science and Engineering Management, 2(3), pp. 178-196. 